Periodica Polytechnica Mechanical Engineering, 65(2), pp. 171-179, 2021

\title{
On the Design of the Manifold for a Race Car
}

\author{
Bevan Hall'1, Greg Wheatley ${ }^{1 *}$, Mohammad Zaeimi² \\ ${ }^{1}$ College of Science and Engineering, James Cook University, QLD 4814 Townsville, 1 James Cook Drive, Australia \\ 2 Mechanical Engineering Department, University of Guilan, 4199613776 Rasht, 5th Kilometer of Persian Gulf Highway, Iran \\ * Corresponding author, e-mail: greg.wheatley@jcu.edu.au
}

Received: 08 October 2020, Accepted: 27 December 2020, Published online: 04 March 2021

\begin{abstract}
This paper involves the design and construction of the intake manifold system of the FSAE car including the air shroud, air filter, throttle body, restrictor plenum, fuel injectors, fuel rail and runners. To ensure the quality, the proposed system is designed based on the FSAE rules. The design process of the intake manifold system will consist of the usual engineering processes including computer modelling, Finite Element Analysis and finally Computational Fluid Dynamics testing in order to determine the validity of the model and to tune the design in order to obtain the optimum performance out of the intake manifold system as a whole.
\end{abstract}

\section{Keywords}

intake manifold, Formula SAE, air shroud, throttle body, restrictor, plenum

\section{Introduction}

The essential modulus of an internal combustion engine is an intake manifold system. In order for a combustion engine to function a number of key components must be included to provide the engine with the three basic ingredients it requires, fuel, air and a spark. The intake manifold assembly of an engine provides two of these ingredients to the engine (namely fuel and air) and plays an integral role in the overall function of the engine. The importance of the presence of fuel, air and a spark in a combustion engine is quite intuitive and with the growing number of cars on the road today, is something the average person is quite familiar with. With that said however, the importance of how, when and the amount of each component that is supplied is key to the overall performance of an engine and is generally what is modified when tuning an engine.

Ceviz and Akın [1] investigated the effect of the intake manifold plenum length/volume on the spark-ignited engines performance. This work revealed that the fuel consumption parameters are highly affect by this variable and the engine performance can be improved by utilizing continuously variable intake plenum length, especially at high load and low engine speeds. Using CFD analysis and noise emission testing, Kennedy et al. [2] developed a new air intake system for a single seat race car for the 2011 formula student competition in Silverstone. The use of rapid prototyping techniques to produce a physical model, the design of a new throttle body, as well as the process for engine remapping and dyno test results were proposed in their study. Butt et al. [3] proposed a novel method based on the sliding mode technique for online prediction the discharge coefficient of throttle body of a gasoline engines. A classical first Sliding mode observer was created to determine intake manifold pressure and the model uncertainty due to the uncertain and time varying discharge coefficient was compensated by the discontinuity/switching signal of sliding mode observer. This discontinuity was utilized to evaluate discharge coefficient as a time varying signal. This coefficient can be considered to tune the intake manifold model to engine measurements.

Potul et al. showed that the gas dynamics of an intake system has a dominant role to evaluate the engine performance [4]. This dynamics are different for fuel injected and carbureted engine and vary according to different factors including angle of the valve, number of cylinders, temperature at inlet and etc. In addition, the effects of intake runner length on the performance characteristics of a four-stroke, single-cylinder spark-ignited engine. It was shown that the runner length had a significant effect on the rpm at which peak value of torque was occurred. Shinde [5] optimized a venturi type restrictor to fit in the intake manifold of a Formula SAE vehicle engine and to allow maximum possible mass flow rate. From Computational Fluid Dynamics (CFD) results, converging and diverging angles of venture according to minimum pressure drop across the restrictor 
were achieved. This type of restrictor was used in reducing power of engine in this work. Rishack et al. [6] studied the effect of different shapes of intake manifold on a single cylinder four stroke gasoline engine using CFD software package FLUINT 6.3 [7]. Both the Navier-Stokes equations and the standard $k$ - $\varepsilon$ turbulence model were used to show the air movement nature and examine the intake manifold optimal geometry. They proposed that a Simulate numerically and experimentally makes it feasible to select an optimized and reliable intake system geometry.

Seshadri [8] improved the reliability and performance of a turbocharged Honda CBR250RR engine which was used by University of Texas Arlington Formula SAE team. This study showed that an unbalanced distribution of air flow among all cylinders lead to Incorrect air/ fuel ratios and subsequently excessive exhaust gas temperatures and pre-ignition detonation. To tackle these issues, a 3D modeling and internal flow distribution are performed using SolidWorks and CFD analysis, respectively. Vichi et al. [9] designed the engine intake system of the Firenze Race Team vehicle with the aim of providing an optimum performance in terms of both the maximum power and the drivability. For this purpose, they firstly optimized the plenum volume in order to limit the influence of the restrictor. Then a novel intake system made up of a variable length duct was considered for improving the engine response time during both the accelerations and decelerations. Shelagowski and Mahank [10] carried out a research project to optimize the geometry of the intake restrictor in order to maximize flow over a range of outlet pressures. The CFD flow modeling software was used to analyze and visualize the fluid flow during the design process. They observed good correlation between the simulations and experiments in terms of flow rate.

According to Formula SAE regulations, in order to limit the maximum power, an air restrictor with a certain diameter should be imposed in the intake line. Romani et al. [11] proposed that an appropriate way to overcome the limitations caused by the restrictor, engine can be equipped with a turbocharger which usually includes a wastegate (WG) valve to avoid knocking phenomena and limit the maximum boost pressure. They showed the implementation of an electronic control system for the WG valve instead of a pneumatic actuator provides higher power values and a more extended torque curve. Using AVL BOOST software [12], the influence of different air restrictor diameters for the performance of Formula SAE car engine was investigated by Melaika et al. [13]. In this work, engine performance related parameters including air intake hydraulic resistance, cylinder Volumetric Efficiency, and engine power and fuel consumption were considered. Da Trindade Marcelino et al. [14] carried out both numerical and experimental analyses to study the impact of the pressure loss generated by the restrictor on the Volumetric Efficiency and fuel consumption variables. It should be noted that the mass of air supplied to the combustion chamber will be reduced by installing the restrictor in the intake system, therefore the behavior of the engine will be affected as a whole due to the alteration of the pressure gradient between the atmosphere and the combustion chamber.

An optimization process was implemented by Lešnik et al. [15] to find the influence of intake trumpet length on air mass flow and pressure fluctuations. They showed that at certain trumpet lengths, pressure fluctuation can increase the flow of air mass per engine cycle, and consequently affects engine-rated power and torque. Sardar and Sardar [16] proposed an intake manifold design which improved the acceleration of the car at the dynamic events at a Formula Student Competition. They used Helmholtz resonator theory and CFD analysis to choose appropriate runner length and plenum volume for the intake system. Prasetyo et al. [17] proposed an article with focus on the design process of the engine intake system and the optimization of both the engine output power and stability for the Bengawan FSAE team vehicle. The system was analyzed via CFD simulation to study some key parameters including the pressure, velocity, and airflow of the intake. Based on the 1D GT-POWER simulation platform, a numerical study was done by Silva et al. [18] on the geometry of an intake manifold of an internal combustion engine. Through an optimization process using the Brent method, it was shown that higher Volumetric Efficiency, effective power and torque can be achieved according to the motor speed conditions.

A CFD modeling of formula student car of intake system was performed by Mohamad et al. [19], which showed better simulation quality compared to the previous models. In order to save a substantial amount of time and resources, using the AVL-Boost software, the intake system was examined acoustically and simulated by means of 1-D gas dynamics.

This paper concerns a formula SAE design project to design the intake manifold, fuel injection system and throttle body for the existing engine. The rest of this paper is organized as follows. In the Section 2, design considerations and selected components are described. The CFD design analysis of the system is proposed in the Section 3. Finally, conclusions are presented in the Section 4. 


\section{Design approach}

The engine that is being used for the James Cook University Formula SAE motorsports car is a liquid cooled, fourstroke transverse four-cylinder engine (Honda CBR 600 F2). It should be mentioned that the intake manifold design should be based on FSAE rules [20].

\subsection{Design considerations}

Cold air shrouds are one of the most highly scrutinized components of a car. The aerodynamics of the design was the largest contributing factor. Smooth transitional flow from the inlet to cylinders is key in order to gain the largest performance potential from the engine. The main components of the throttle body remain fairly constant between all of the different designs but the method by which each is controlled (be it electronically or mechanically) differs between each design. The FSAE rules are very specific about what designs for throttle body are allowed for use on the FSAE car. The only factor requiring selection being the inlet and outlet diameters of the throttle body pipes [21].

The FSAE restrictor did not provide the optimum performance airflow to the engine and as such minor modifications to the design such as diameters and contraction rate were altered during the design selection process. There were two main choices as to which fuel injection system would be used for the FSAE car, the fuel injection system or the carburettor system. The system chosen for this application was the fuel injection system as it allows for fine-tuning of the relatively small engine at hand to give higher performance while still having appropriate fuel economy. There are numerous considerations in the design of the plenum that would greatly influence the overall design of the intake system. The FSAE car engine is positioned such that it is possible to employ a centre fed plenum and take advantage of the excessive space above the engine. The location of the intake on a plenum greatly varies its shape, as the plenum must facilitate streamline flow.

There is no universally correct volume for a plenum as the most efficient volume is a function of the engine displacement, conditions where it is being used and the application of the vehicle. Because of this it is advantageous to build a plenum with a variable volume. By placing a spacer between the two-plenum halves (effectively adjusting the plenums volume), the engine can be tuned to specific conditions efficiently [22]. In designing the runners, there was little variation between the existing industry designs. The cross sectional shape was chosen to be circular due to the inlet port mating and the improved flow properties at the boundaries over that of a square or oval shaped runner.

\subsection{Components of the selected design}

The cold air shroud was designed such that it would allow the required amount of smooth laminar flow. The triangular inlet of the design was chosen to maximise the amount of air captured by the shroud whilst remaining within the constraints of the frame (see Fig. 1).

The taper to the circular outlet was included for simplicity in order to provide the required throttle body inlet shape whilst maintaining smooth transitional changes in the airflow.

The inlet and outlet radii of the throttle body $(36.276 \mathrm{~mm}$ and $28.03 \mathrm{~mm}$, respectively) were the only key design factors of the throttle body, which was a pre-fabricated design. The diameters were chosen such that a large enough volume of airflow was able to enter the plenum (see Fig. 2).

Similarly the inlet and outlet diameters of the restrictor were the only key design factors and needed to be designed such that they matched the diameters of the throttle body and the plenum respectively. The geometry of the restrictor is proposed in Fig. 3.

As shown in Fig. 4, the fuel injection system consists of two major components, the four fuel injectors and the fuel rail. Both the fuel injectors and fuel rail are pre-fabricated

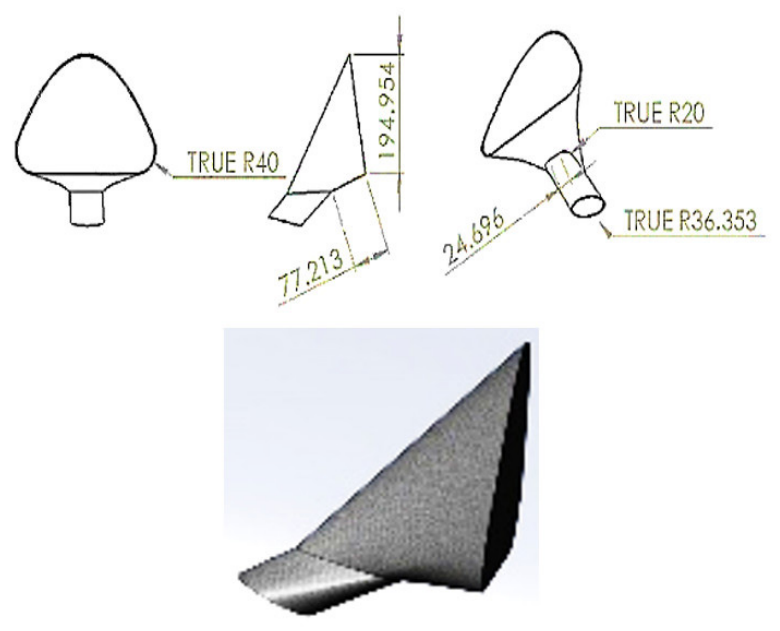

Fig. 1 Cold air shroud geometry

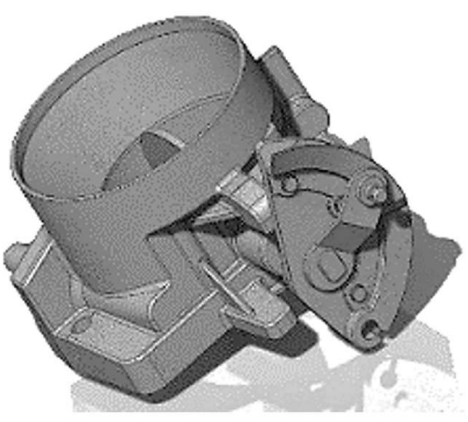

Fig. 2 Throttle body geometry 


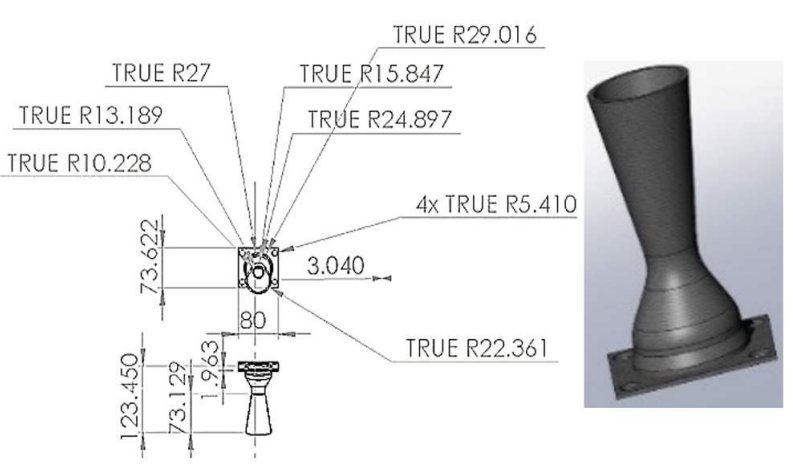

Fig. 3 Restrictor geometry

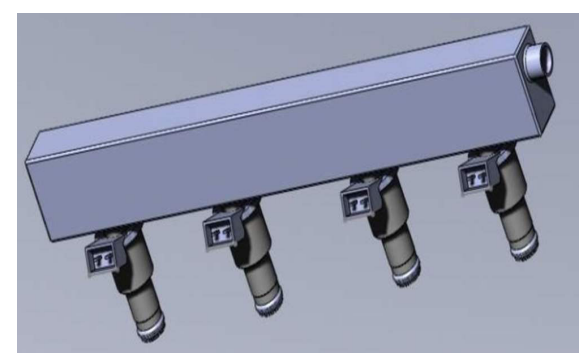

Fig. 4 Fuel injector geometry

designs for the $600 \mathrm{cc}$ engine and therefore no additional geometrical dimensions had to be designed for the fuel injection system.

The plenum consists of three different components; four velocity stacks and an upper and lower plenum half, see Fig. 5. The design of the velocity stacks has little influence on the performance of the plenum, however it must have a height sufficient to draw air from the high velocity pocket and a diameter to compliment the runners. The lower plenum acts to house the velocity stacks and form a large portion of the plenum volume. It will also have a flange located on the top edge to compliment the flange on the top half of the plenum. The upper plenum has a flange on the lower edge to facilitate the lower half, as well as harbouring the intake port and dual plenum slit.
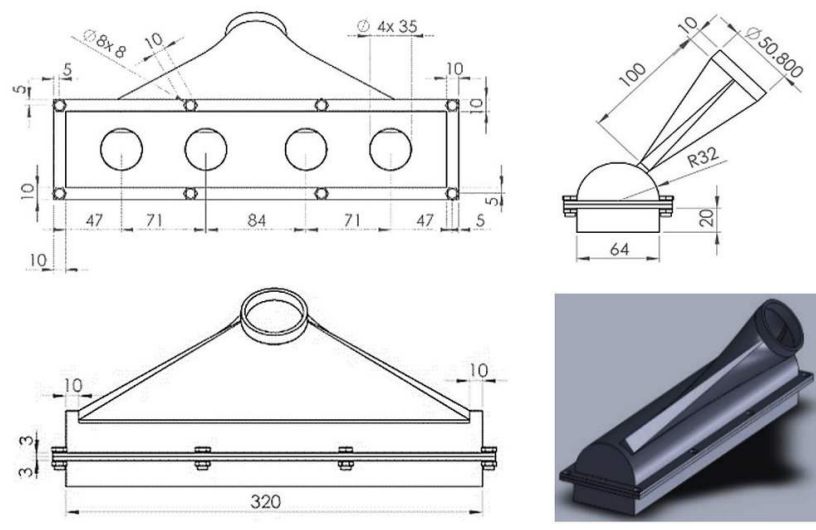

Fig. 5 Plenum geometry
There is no optimal plenum volume as the tune of the engine will be different for each application. However, a larger plenum will produce a higher maximum power but a smaller plenum has a better throttle response. As the FSAE car will most likely be undergoing rapid acceleration and deceleration as opposed to maintaining high revs, it is advantageous to have a smaller plenum volume.

A general guide is that the minimum plenum volume should be about $2 x$ the engine displacement of $600 \mathrm{cc}$. Therefore the volume of the plenum should be approximately $1.2 \mathrm{~L}$. However, to enhance the tune ability of the engine the design has been constructed such that the volume can be adjusted [22].

Five separate components make up the runner assembly. The injector mounts, joint tubes, outer sleeves, runner lengths and O-ring runner seals are shown in Fig. 6. In order to provide a suitable design that may be easily modified at a later date, the injector mounting assembly has been made easily removable. This means that the runner is not permanently attached to the outer tube.

In designing the runner assembly, two major factors of the design were mass air flow and wave theory. In designing for the former, the amount of air the engine draws at maximum revolutions had to be taken into account. The cross sectional area had to then be designed such that the flow did not exceed a Mach index of 0.5. The calculation for determining the airflow can be seen below.

The engine operates on a four-stroke cycle having a displacement of $599 \mathrm{~cm}^{3}$ and operates at a maximum of $12000 \mathrm{rpm}$. On a one-cylinder basis, the piston completes a cycle every $2 \mathrm{rpm}$ of the crankshaft. This includes each of the intake, compression, power and exhaust strokes. Theoretically, during each cycle the engine draws in $149.75 \mathrm{~cm}^{3}$ of air (assuming a Volumetric Efficiency (V.E.) of $100 \%$ which of course is not true in reality). The V.E. of the engine is likely to be between $75-85 \%$ (as is the standard for most production engines) and will be significantly lower once the restrictor is fitted. Peak Volumetric Efficiency occurs at the peak torque of the engine, which is $10500 \mathrm{rpm}$ for this particular engine. For the basis of

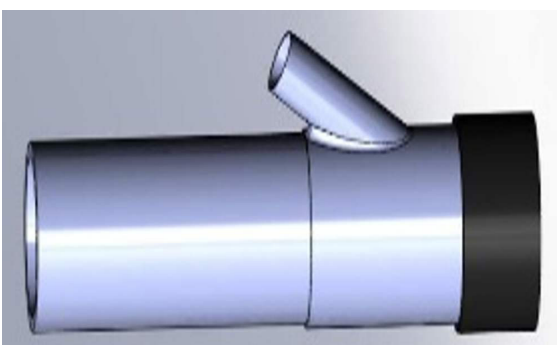

Fig. 6 Runners 
this calculation however, it is assumed that the V.E. of the engine is $75 \%$ at $12000 \mathrm{rpm}$, which will tend to overestimate the volume of air and as such result in a design which performs better than the minimum requirement.

At $12000 \mathrm{rpm}$, this translates to $673.88 \mathrm{~L} /$ minute per cylinder and $2695.5 \mathrm{~L} /$ minute for the engine as a whole. The runner cross section was chosen as circular, due to the predicable flow that would occur such as high velocity in the center of the flow and a theoretical zero value at the edges. This shape is also better suited than that of a square cross sectional and is easier to manufacture.

Due to the high speeds that will occur within the runner, the runner cross sectional area is an important design feature. At such high velocities of flow (for the current $36 \mathrm{~mm}$ inside diameter, the flow rate of $0.0449 \mathrm{~m}^{3} / \mathrm{s}$ and cross sectional area of $1.0179 \times 10^{-3} \mathrm{~m}^{2}$, the velocity of the flow will be $44.145 \mathrm{~m} / \mathrm{s}$ which is significantly less than a Mach index of 0.5 ), any slight steps or downs will create a large amount of turbulence. Therefore this value has been chosen as an inside diameter with a wall thickness of $3 \mathrm{~mm}$ to suit the rubber mount currently situated on the engine. This eliminates any steps in geometry. This size runner has also proven to be suitable in the modelling of the system.

The runner length also affects the torque characteristics of the engine. Longer runners were chosen over a shorter design for two reasons. Firstly, for the FSAE competition, the engine will not be at the higher end of its rpm range for any significant period of time due to the nature of the designed course. A broad midrange engine is better suited to the challenges presented. Secondly, having a longer intake runner allows ram tuning is beneficial.

Ram tuning includes designing the length of the runner to reverberate the pressure wave resulting from the intake valve slamming shut to be timed so that at a thin band of rpm it will enter the open intake valve and boost Volumetric Efficiency. To design for this, several calculations had to be performed. As the engine completes its cycle, it is the camshaft that opens and closes the intake and exhaust valves. The camshaft profile determines the duration and lift of the valves. It is this duration that needs to be calculated. First however, the rpm range must be chosen. The engine currently produces maximum torque at $10500 \mathrm{rpm}$. It is torque that accelerates the vehicle. As it is assumed that the current camshaft is to be retained, the value of $10500 \mathrm{rpm}$ will be used. The camshaft specifications for this engine (assuming stock cam fitted, as appears to be) are the intake opens $22^{\circ}$ before top dead centre and closes at $43^{\circ}$ after bottom dead centre. Thus the duration for which the intake valve is open can be calculated to be $245^{\circ}$; sum of $22^{\circ}, 43^{\circ}$ and $180^{\circ}$ ).

This means that the intake is open for 245 degrees of the cranks rotation. The crank rotates twice for the intake to open once. This means that the intake is closed for $475^{\circ}$; the difference of $720^{\circ}$ and $245^{\circ}$; of a crank rotation. It is also necessary to find the time that the intake valve is closed such that the pressure wave can be timed to be back at the intake when it is opening again. Thus converting $10500 \mathrm{rpm}$ gives $175 \mathrm{rev} / \mathrm{s}$. Since one revolution is equal to 360 degrees, the crankshaft is travelling at 63000 degrees per second.

Hence the period that the intake is closed is 475 degrees of the crankshaft cycle which is equal to $7.539 \mathrm{~ms}$ (475 degrees / (63000 degrees / second)). This period is commonly referred to as the critical time factor. How far the pressure wave travels in this time must also be calculated. Assuming an ambient temperature of $200{ }^{\circ} \mathrm{C}$, the speed of sound in air is $343.2 \mathrm{~m} / \mathrm{s}$. Therefore in $7.539 \mathrm{~ms}$ the pressure wave will travel $2.587 \mathrm{~m}$.

For a runner, this pressure wave must travel up and back. So for the first "bounce" of this pressure wave to return to the valve the runner must be 1.294 meters long. This is not a reasonable length. Table 1 shows values of the harmonic or "bounce" numbers and the length of the intake runner required to take advantage of each. The first harmonic is the most energetic as it has only had to reverberate once. This reverberation and travelling through the medium takes energy away from the pulse and so it is advantageous to use the earlier harmonics over the latter ones.

Each harmonic consists of the pressure wave travelling from the intake valve up the port, up the runner, into the plenum and hitting the back of the plenum and travelling back down this track. The lengths given in Table 1 are representative of this as a total dimension. For example, on the $4^{\text {th }}$ harmonic the pressure wave travels up the intake and back 3 times to find that the valve is closed and continues to reverberate. On the $4^{\text {th }}$ return however, the intake valve is now open and the pressure waves enters the combustion chamber. Thus it is desirable that this fourth value be used for the design. The lengths of the earlier harmonics are too large to be used within the intake system and the last two don't offer as much gain as the fourth. A total intake length

Table 1 Runner lengths and corresponding harmonics

\begin{tabular}{lcccccc}
\hline Harmonic & 1 & 2 & 3 & 4 & 5 & 6 \\
\hline Length $(\mathrm{m})$ & 1.294 & 0.647 & 0.216 & 0.324 & 0.259 & 0.215 \\
\hline
\end{tabular}


(plenum to valve) was then chosen to be $324 \mathrm{~mm}$. The port depth of the engine was measured to be $105 \mathrm{~mm}$, the rubber mount to be $6 \mathrm{~mm}$, the joint tube to be $18 \mathrm{~mm}$ and the designed plenum depth as $60 \mathrm{~mm}$. These values are taken off the length of $135 \mathrm{~mm}$ which the runner assembly required. The final design of the internal surface of the runner assembly is then of circular cross section, diameter $36 \mathrm{~mm}$, runner body thickness $3 \mathrm{~mm}$ (although each component varies) and length of $135 \mathrm{~mm}$.

\subsection{Force calculations}

The forces acting on this system consist of its own weight, vibrations resulting from operation of the engine, wind pressure acting on the intake and any inertial forces resulting from acceleration whether straight line or cornering. Due to the low mass of the system in comparison to the strength of the steel fixtures required to mount it, the weight and inertial forces need not be taken into account. Rubber mounts are specified to dampen the vibrations form the operation of the engine. Also, the wind pressure at $100 \mathrm{~km} / \mathrm{h}$ on the intake has been calculated below, assuming the intake is a flat plate. This assumption will yield an overestimate of the forces involved.

$P=\frac{1}{2}\left[\rho_{\text {air }} \times v_{\text {air }}^{2} \times S\right]$,

where $\rho_{\text {air }}$ and $v_{\text {air }}$ are air density and velocity, respectively; $P$ and $S$ are correspondingly the pressure and the shape factor for flat surface. Thus:

$P=\frac{1}{2}\left[1.25 \times 27.77^{2} \times 1.6\right]=771.17 \frac{\mathrm{N}}{\mathrm{m}^{2}}$.

Calculating the force $F$ on the area of intake gives:

$$
F=P \times A=771.17 \times 0.04=30.84 \mathrm{~N} .
$$

\section{Design analysis and results}

The meteorological conditions of the track site where the car is to be raced should be sourced to determine the relative parameters of the surrounding air (see Table 2).

From these values Solidworks CFD analyses were conducted for each component and for the system as a whole.

For each components, the CFD analysis were carried out for three cases including wide open throttle velocity, peak

Table 2 Meteorological averages

\begin{tabular}{lccc}
\hline Parameter & Humidity & Temperature & Wind speed \\
\hline Value & $70 \%$ & $21.125^{\circ} \mathrm{C}$ daily $\max$. & $45 \mathrm{~km} / \mathrm{h}$ \\
\hline
\end{tabular}

velocity and idle velocity. They are summarized as follows before presenting flow analysis of the whole system.

For the cold air shroud were desirable throughout all 3 cases. The flow remains smooth and laminar and confirms the validity of the design for the purpose of the FSAE car. For the restrictor, smooth laminar flow has been maintained throughout the restrictor throughout the various velocities-confirming the validity of the design.

The high-pressure pocket as a result of the backpressure of the slit forces the flow to disperse along the length of the plenum. This shows that the slit is effective at spreading the flow to all four cylinders.

The velocity profile over the velocity stack entrance shows relatively uniform and high intake velocity. The velocity profile of the flow through the dispersion slit shows that the slit effectively increases the flow width from $50.8 \mathrm{~mm}$ at the intake to the full spread of the cylinders at $246 \mathrm{~mm}$. This confirms the validity of the design and the effectiveness of the intake slit.

With a $20 \mathrm{~mm}$ spacer inserted, the flow in the plenum has more room to recirculate, creating more turbulence. For a $40 \mathrm{~mm}$ spacer, the flow on the left hand side of the plenum is disrupted greatly and the slit loses its effectiveness. As a result, the flow in the center of the plenum is of a higher velocity and flow on the left hand side has stagnated. Furthermore, with a $60 \mathrm{~mm}$ spacer inserted, the plenum forms two distinct vortexes over pairing cylinders. The flow through the slit is disrupted because of this with the flow not utilizing the full width of the slit. This results in higher velocities through the center, probably exacerbating the vortices.

The runner design has been proved to be valid maintaining smooth laminar flow throughout the various flow cases.

An intermediate assembly comprising of the restrictor and plenum was constructed in Solidworks and a transient analysis conducted upon it in order to gain an understanding of the nature of the components when in an assembly and under transient conditions.

Form Figs. 7 to 10, the transient analysis of the intermediate system at wide-open throttle flow velocity has demonstrated the effectiveness of the plenum and the restrictor. The slit produces strong and even flow to the entire length of the plenum, ensuring the entire plenum provides adequate flow to all four cylinders. This final transient flow analysis has confirmed the effectiveness and validity of the center fed plenum design operating in conjunction with the flow restrictor. 

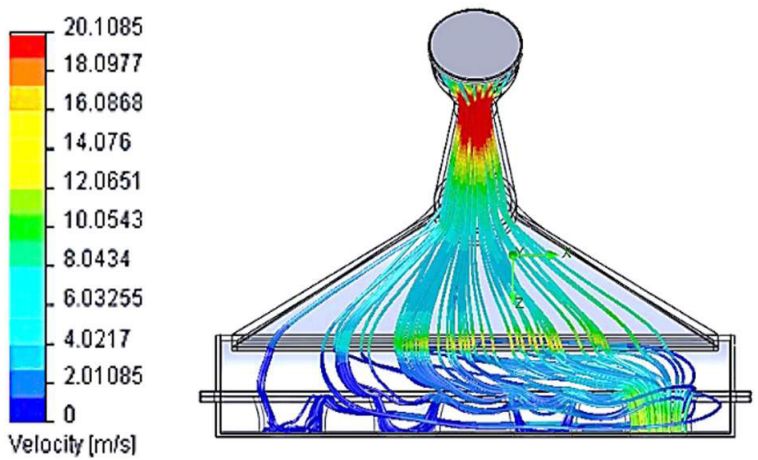

Fig. 7 Transient flow analysis - frame 1
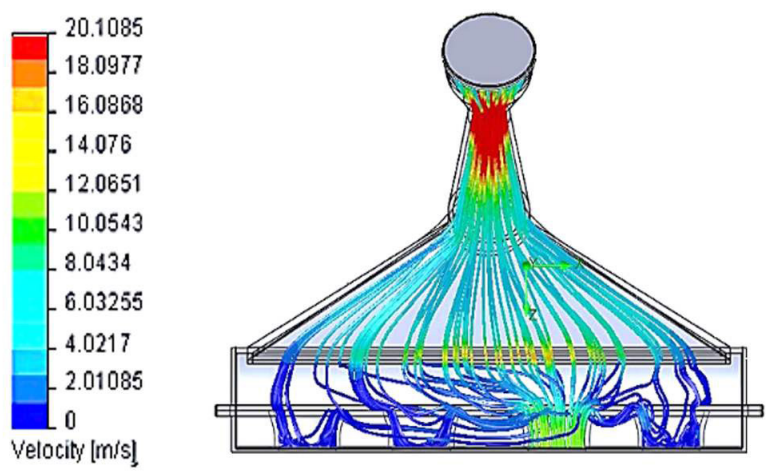

Fig. 8 Transient flow analysis - frame 2
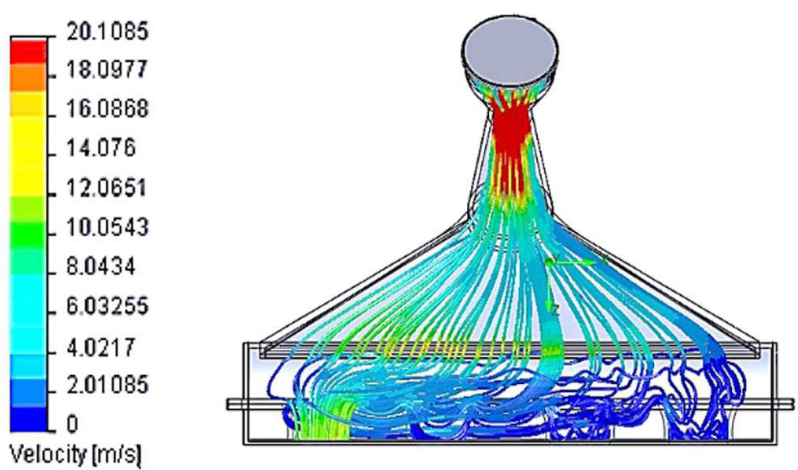

Fig. 9 Transient flow analysis - frame 3
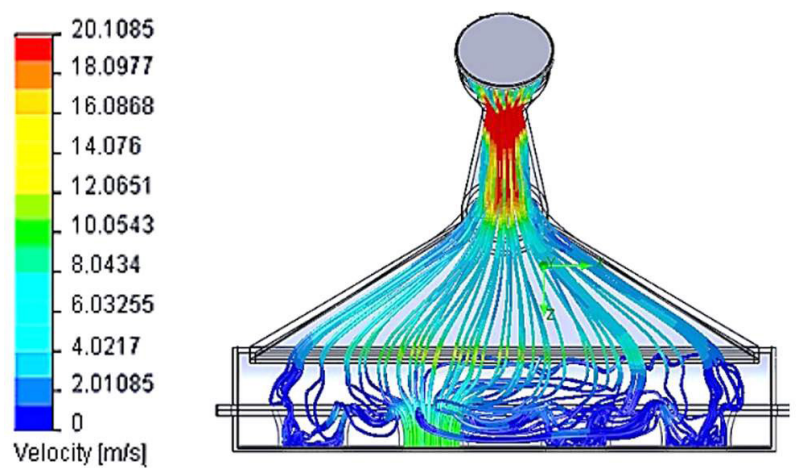

Fig. 10 Transient flow analysis - frame 4
Results for the whole system are shown in Figs. 11 to 16 in key frame format from the animation. As can be seen, the design performs well maintaining the design flow characteristics throughout the cycle.

\section{Conclusion}

This paper provides key considerations for designing and analyzing the manifold for a Formula SAE vehicle produced by James Cook University students. The existing
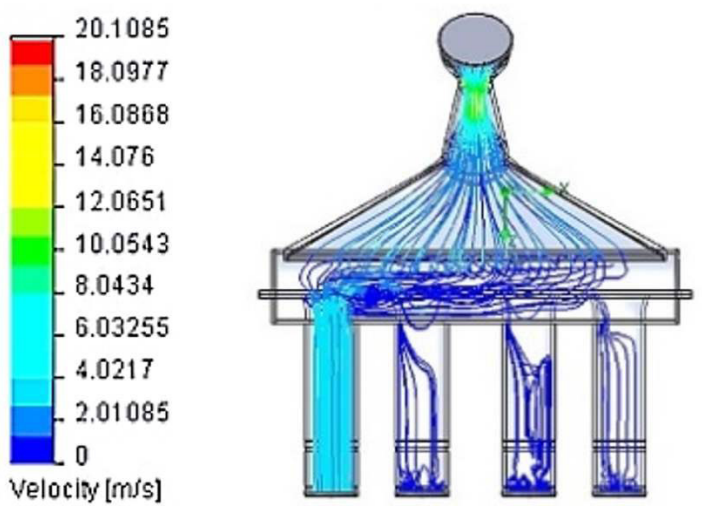

Fig. 11 Flow analyses summary - frame $1(0.0044 \mathrm{sec})$
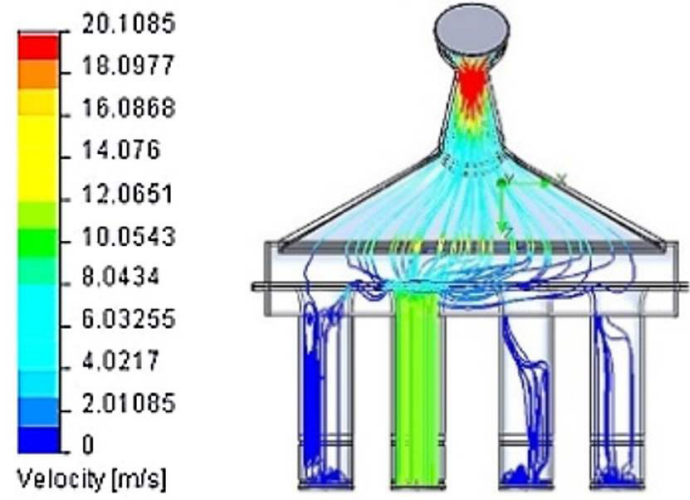

Fig. 12 flow analyses summary - frame $2(0.0052 \mathrm{sec})$
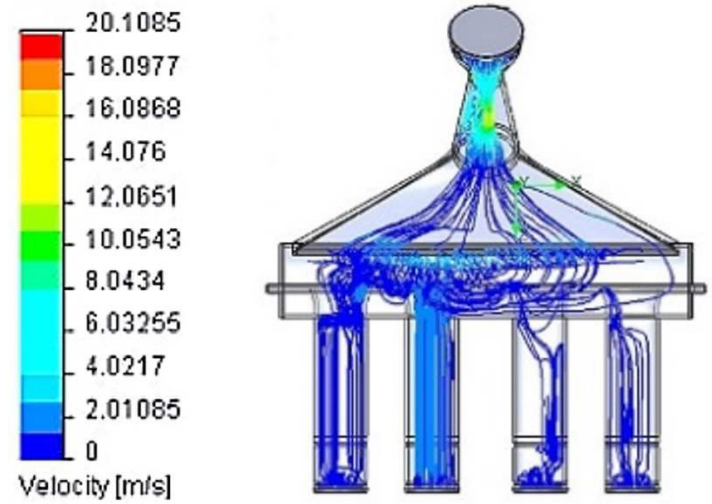

Fig. 13 Flow analyses summary - frame $3(0.0064 \mathrm{sec})$ 

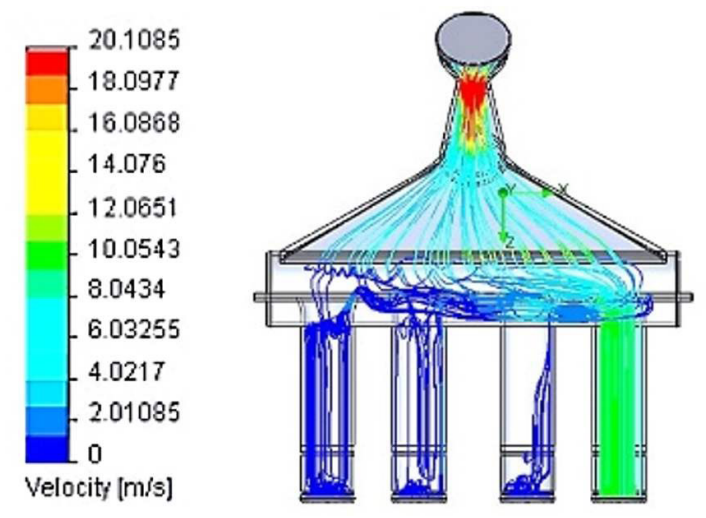

Fig. 14 Flow analyses summary - frame $4(0.007 \mathrm{sec})$
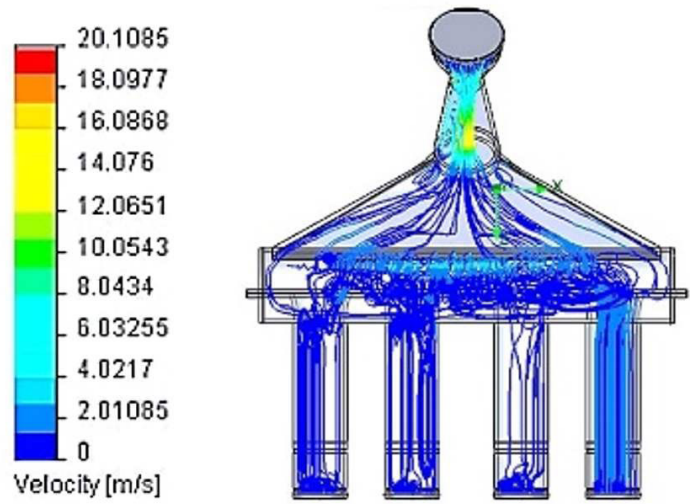

Fig. 15 Flow analyses summary - frame $5(0.0083 \mathrm{sec})$
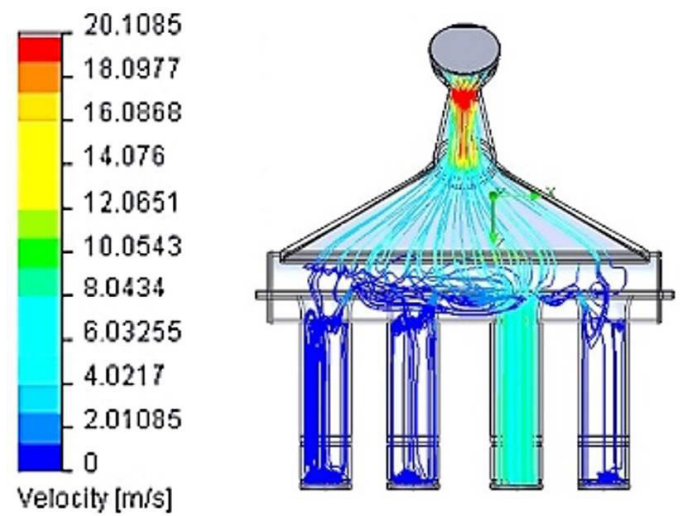

Fig. 16 Flow analyses summary - frame $6(0.0088 \mathrm{sec})$

\section{References}

[1] Ceviz, M. A., Akın, M. "Design of a new SI engine intake manifold with variable length plenum", Energy Conversion and Management, 51(11), pp. 2239-2244, 2010.

https://doi.org/10.1016/j.enconman.2010.03.018

[2] Kennedy, D., Woods, G., Forrest, D. "Development of a New Air Intake and Exhaust System for a Single Seat Race Car", PhD Thesis, Dublin Institute of Technology, 2003. design car consists of a welded steel tubing frame and a 4-stroke 600CC (Honda CBR 600 F2) engine. The most important parts of the design were:

- Aerodynamics: the flow of air into the engine must be laminar and at the correct velocity. The design must enable a sufficient amount of air to enter the manifold whilst not impacting too heavily on the overall aerodynamics of the car.

- Atomization: the quality of the fuel to air mixture that enters the cylinder is vital to the overall function of the engine. Sufficient atomization of the fuel within the air is required in order for the engine to function efficiently.

- Plenum volume: the volume of the plenum is a governing factor in the throttle response of the engine, and is directly related to the engines displacement and intended operational rev. range. An accurately tuned plenum volume is essential to maximize the performance of an engine.

- Runner length: optimizing the runner length relative to the specifications of the engine and the current design constraints is vital for increased performance of the system. Designing for bulk particle flow and taking advantage of wave theory (harmonic/ram induction) will greatly benefit this system.

Each part will require Solidworks and ANSYS modelling to ensure that the flow characteristics, the geometrical dimensions and the construction materials used meet the various design constraints.

In future work, the focus will be on the influence of the size of receiver and runners on the intake process, the losses in the intake system and the influence of neighboring cylinders, and optimizing the parameters of intake system including the length of the runners and the volume of the receiver.

[3] Butt, Q. R., Bhatti, A. I., Mufti, M. R., Rizvi, M. A., Awan, I. "Modeling and online parameter estimation of intake manifold in gasoline engines using sliding mode observer", Simulation Modelling Practice and Theory, 32, pp. 138-154, 2013. https://doi.org/10.1016/j.simpat.2012.12.001

[4] Potul, S., Nachnolkar, R., Bhave, S. "Analysis Of Change In Intake Manifold Length And Development Of Variable Intake System", International Journal OF Science \& Technology Research, 3(5), pp. 223-228, 2014. 
[5] Shinde, P. A. "Research and optimization of intake restrictor for Formula SAE car engine", International Journal of Scientific and Research Publications, 4(4), pp. 4-8, 2014.

[6] Rishack, Q. A., Dakhil, S. F., Obaid, M. K. "Theoretical and Experimental Study of the Intake Manifold Effect on the SI Engine Performance", Basrah Journal for Engineering Sciences, 14(2), pp. 200-215, 2014.

[7] Ansys "Ansys Fluent 6.3", [computer program] Available at: https://www.ansys.com/products/fluids/ansys-fluent [Accessed: 07 October 2020]

[8] Seshadri, S. "Design And CFD Analysis Of The Intake Manifold For The Honda CBR250RR Engine", MSc Theses, The University of Texas at Arlington, 2015.

[9] Vichi, G., Romani, L., Ferrari, L., Ferrara, G. "Development of an Engine Variable Geometry Intake System for a Formula SAE Application", Energy Procedia, 81, pp. 930-941, 2015.

https://doi.org/10.1016/j.egypro.2015.12.149

[10] Shelagowski, L. M., Mahank, T. A. "CFR Formula SAE Intake Restrictor Design and Performance", In: 2015 ASEE North Central Section Conference, Cincinnati, OH, USA, 2015, pp. 1-7.

[11] Romani, L., Vichi, G., Bianchini, A., Ferrari, L., Ferrara, G. "Optimization of the Performance of a Formula SAE Engine by Means of a Wastegate Valve Electronically Actuated", Energy Procedia, 101, pp. 654-661, 2016. https://doi.org/10.1016/j.egypro.2016.11.083

[12] AVL "AVL BOOST", [computer program] Available at: https:// www.avl.com/boost [Accessed: 07 October 2020]

[13] Melaika, M., Rimkus, A., Vipartas, T. "Air Restrictor and Turbocharger Influence for the Formula Student Engine Performance", Procedia Engineering, 187, pp. 402-407, 2017. https://doi.org/10.1016/j.proeng.2017.04.392

[14] da Trindade Marcelino, E., Barbosa da Rocha, Á., Pereira Duarte Correia, L. A., Calazans Duarte, R. N. "Numerical and Experimental Study of Pressure Loss at the Intake Manifold of a Formula-SAE Vehicle", In: 24th ABCM International Congress of Mechanical Engineering, Curitiba, Brazil, 2017, pp. 1-8. https://doi.org/10.26678/ABCM.COBEM2017.COB17-0766
[15] Lešnik, L., Mlakar, N., Biluš, I., Kegl, B. "The Optimization of a Race Car Intake System", Journal of Energy and Technology, 10(3), pp. 11-23, 2017.

[16] Sardar, P., Sardar, A. "Designing of intake manifold for Formula Student car", World Journal of Engineering, 15(3), pp. 402-406, 2018. https://doi.org/10.1108/WJE-09-2017-0289

[17] Prasetyo, B. D., Ubaidillah, Maharani, E. T., Setyohandoko, G., Idris, M. I. "Computational studies of an intake manifold for restricted engine application", AIP Conference Proceedings, 1931(1), Article Number: 030035, 2018. https://doi.org/10.1063/1.5024094

[18] Silva, E. A. A., Ochoa, A. A. V., Henríquez, J. R. "Analysis and runners length optimization of the intake manifold of a 4-cylinder spark ignition engine", Energy Conversion and Management, 188, pp. 310-320, 2019. https://doi.org/10.1016/j.enconman.2019.03.065

[19] Mohamad, B., Karoly, J., Zelentsov, A. "CFD Modeling of Formula Student Car Intake System", FACTA Universitatis Series: Mechanical Engineering, 18(1), pp. 153-163, 2020. https://doi.org/10.22190/FUME190509032M

[20] SAE International "2011 Formula SAE Rules", SAE International, Warrendale, PA, USA, 2011. Available at: http://www.fsaeonline. com/content/2011\%20FSAE\%20Rules-Revision\%20FINAL.pdf [Accessed: 07 October 2020]

[21] Pogorevc, P., Kegl, B. "Intake system design procedure for engines with special requirements", Proceedings of the Institution of Mechanical Engineers Part D: Journal of Automobile Engineering, 220(2), pp. 241-252, 2006. https://doi.org/10.1243/095440706X72763

[22] Hamilton, J. L., Cowart, J. S., Lee, J. E., Amorosso, R. E. "The Effects of Intake Plenum Volume on the Performance of a Small Normally Aspirated Restricted Engine", Journal of Engineering for Gas Turbines and Power, 133(1), Article Number: 012801, 2008.

https://doi.org/10.1115/1.4001071 